\title{
Pharmacy Technician Workforce in Saudi Arabia over Twelve Years (2006-2017)
}

\author{
Yousef Ahmed Alomi* iD, General \\ Administration of Pharmaceutical Care, Minis- \\ try of Health, Riyadh, Saudi Arabia. \\ Saeed Jamaan Alghamdi, Gen- \\ eral Administration of Pharmaceutical Care, \\ Ministry of Health, Riyadh, SAUDI ARABIA. \\ Radi Abdullah Alattyh, General \\ Administration of Pharmaceutical Care, Minis- \\ try of Health, Riyadh, SAUDI ARABIA.
}

\section{Correspondence:}

Dr. Yousef Ahmed Alomi, The Former General Manager of General Administration of Pharmaceutical Care, Former Head National Clinical pharmacy and pharmacy practice, Former Head, Pharmacy R\&D Administration, Ministry of Health, P.O.BOX 100 Riyadh-11392, Saudi Arabia.

Phone no: +966504417712

E-mail:yalomi@gmail.com
Received: 25-02-2019;

Accepted: 31-04-2019

Copyright: (C) the author(s), publisher and licensee International Journal of Pharmacology and Clinical Sciences. This is an open-access article distributed under the terms of the Creative Commons Attribution Non-Commercial License, which permits unrestricted non-commercial use, distribution, and reproduction in any medium, provided the original work is properly cited.

This is an open access article distributed under the terms of the Creative Commons Attribution-NonCommercial-ShareAlike 4.0 License

Access this article online

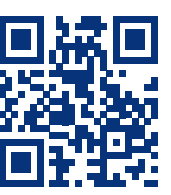

www.ijpcs.net

DOI:

10.5530/ijphs.2019.8.26

\begin{abstract}
Objectives: To explore the workforce of pharmacy technician at Ministry of Health $(\mathrm{MOH})$ institutions over the past twelve years (2006-2017) in the Kingdom of Saudi Arabia. Methods: It is a retrospective analysis of twelve years (2006-2017) of Ministry of Health pharmacy technician workforce at hospital practice. All data derived from the Ministry of Health Statistical Year Books and any missing appropriate information about pharmacy technician workforce, that's will be estimated through allied healthcare professional's data in each region including gender or nationality. It included pharmacy technician and exclude all types of pharmacists or clinical pharmacist's workforces at $\mathrm{MOH}$ hospital and Primary Health Care Centers (PHCs) settings. All calculations were based on $\mathrm{MOH}$ workforce standards of hospitals and PHCs. All calculation was done using Microsoft Excel version ten. Results: The total number of pharmacy technician in all sectors, hospitals, primary healthcare centers and medical affairs administration increased from 4,289 to 8,373 over twelve years to 1.96-fold increments (20062017). The number of Saudi pharmacy technician increased from 3,064 to 8,061 to 2.63-fold increments while non-Saudi pharmacy technician decreased from 1,225 to 312 to 3.92-fold reductions. The rate of pharmacy technician to pharmacist decreased from 6.7 to 2.2 to 3.05 -fold ratio reductions while the pharmacy technician per 10,000 population increased from 2.67 to 4.29 to 1.61 -fold incremental ratio over the past twelve years. Conclusion: The pharmacy technician worked at the Ministry of Health institutions increased over the past twelve years. The Saudi pharmacy technician was increased with reduction of non-Saudi nationality. The male gender more than female. The ratio of pharmacy technician to pharmacist was reduced by time. The pharmacy technician workforces needed to explore at all healthcare institutions in the Kingdom of Saudi Arabia.

Keywords: Pharmacy technician, Hospital, Health, Centers, Workforce, Ministry of Health, Saudi Arabia.
\end{abstract}

\section{INTRODUCTION}

The analysis, workforce of pharmacy staff is very critical in healthcare practice. That is related to detect the demand or forecasting of the pharmacy staff. Besides, to determine the Human Resources of the pharmacy department. One of the strategic goals of the pharmacy strategic plan and updated plan with vision 2030 was the pharmacy workforce, including the pharmacy technician. ${ }^{[1,2]}$ The Ministry of Health released the standard of pharmacist workforce requirements in the hospitals and primary healthcare centers. ${ }^{[3,4]}$ The pharmacy technician workforce standard has not existed yet. Several studies published locally for the pharmacist workforce or demand while pharmacy technician not investigated. ${ }^{[5-9]}$ However, the pharmacy technician workforce discussed during the mass gatherings hajj period only. ${ }^{[10-12]}$ The pharmacy technician workforce analysis at all healthcare sectors, including hospitals or primary healthcare centers or medical affairs administration, not existed. Besides, the pharmacist to pharmacy technician in the actual practice did not determine in Saudi Arabia or Gulf and Middle East countries based on the best of the author's knowledge. The study aimed to declare the pharmacy technician workforce at all healthcare institutions of the Ministry of Health in the Kingdom of Saudi Arabia.

\section{METHODS}

It is a retrospective analysis of twelve years (20062017) of MOH hospitals, primary healthcare center (PHCs) and $\mathrm{MOH}$ administration pharmacy technician's workforce. All data derived from the Ministry of Health Statistical Year Books and any missing appropriate information about pharmacy technician workforce, that's will be estimated through allied healthcare professionals data at each region including gender or nationality. ${ }^{[13-24]}$ It included all types of pharmacy technicians included in the study while excluded all pharmacists or clinical pharmacist's workforces at $\mathrm{MOH}$ intuitions (Medical affairs and hospitals or primary healthcare centers). All pharmacy technicians expected to provide pharmaceutical according to the American Society of Health-System Pharmacist (ASHP) definition and requirements. All types of' pharmacy services based on the Saudi Central Board of hospital accreditation, Joint Commission on Hospital Accreditation, ASHP best practice standards and general administration of the pharmaceutical care strategic plan. ${ }^{[1,25-28]}$ All pharmacy technician's works 
at $\mathrm{MOH}$ hospitals or administration or non$\mathrm{MOH}$ government hospitals and primary care centers excluded from the studies. All private hospital or community pharmacy technician excluded from the study. All calculations were based on $\mathrm{MOH}$ workforce standards of hospitals and PHCs. All calculation was done using Microsoft Excel version ten. The calculations were for a total twenty-one regions; the hospitals and primary health care centers, distribution numbers in each year, the annual pharmacy technician distribution numbers, the ratio of the pharmacy technician's per pharmacist, the ratio of the pharmacy technician's per populations and the gender distribution of pharmacy technician at overall Saudi Arabia.

\section{RESULTS}

The total number of pharmacy technician at all sectors, hospitals, primary healthcare centers and medical affairs administration increased from 4,289 to 8,373 over twelve years to 1.96 fold increments (2006-2017). The number of Saudi pharmacy technician increased from 3,064 to 8,061 to 2.63 -fold increments while non-Saudi pharmacy technician decreased from 1,225 to 312 to 3.92 -fold reductions. The number of Saudi males of pharmacy technician increase 2,887 to 7,149 to 2.48-fold increments, while Saudi female increase 177 to 912 to 5.15fold increments over twelve years. The male gender of non-Saudi pharmacy technician decreased from 744 to 56 to 13.29 -fold reductions, while non-Saudi female reduced from 481 to 256 to 1.88 -fold reductions. The rate of pharmacy technician to pharmacist decreased from 6.7 to 2.2 to 3.05 -fold ratio reductions, while the pharmacy technician per 10,000 population increased from 2.67 to 4.29 to 1.61 -fold incremental ratio over the past twelve years (Table 1 and Figure 1).

The total number of pharmacy technician at hospitals increased from 2,899 to 6,619 over twelve years to 2.28-fold increments (20062017). The number of Saudi pharmacy technician increased from 2,071 to 6,373 to 3.1-fold increments, while non-Saudi pharmacy technician decreased from 828 to 246 to 3.36 -fold reductions. The number of Saudi males of pharmacy technician increase 1,951 to 5,652 to 2.89 -fold increments, while Saudi female increase 120 to 721 to 6.00 increments over twelve years. The male gender of non-Saudi pharmacy technician decreased from 503 to 44 to 11.43 -fold reductions, while non-Saudi female reduced from 325 to 202 to 1.6 -fold reductions. The rate of pharmacy Technician per hospital increased 13.18 to 23.47 , while the rate of pharmacy Technician per bed increased from 0.09 to 0.15 . The rate of pharmacy technician to pharmacist decreased from 4.54 to 2.04 with 2.23 -fold ratio reductions, while the pharmacy technician per 10,000 population increased from 1.86 to 3.39 to 1.82 -fold incremental ratio over the past twelve years (Table 2).

The total number of pharmacy technician at PHCs increased from 891 to 1,623 over twelve years to 1.82-fold increments (2006-2017). The number of Saudi pharmacy technician increased from 637 to 1,562 to 2.59 -fold increments, while non-Saudi pharmacy technician decreased from 254 to 61 to 4.16 -fold reductions. The number of Saudi males of pharmacy technician increase 600 to 1,386 to 2.31 -fold increments, while Saudi female increase 37 to 176 to 4.76 increments over twelve years. The male gender of non-Saudi pharmacy technician decreased from 154 to 11 to 14 -fold reductions, while non-Saudi female reduced from 100 to 50 to 2 -fold reductions. The rate of pharmacy Technician per PHCs increased 0.46 to 0.69 , while the rate of pharmacy technician to pharmacist decreased from 11.46 to 3.47 to 3.34-fold ratio reductions, while the pharmacy technician per 10,000 population increased from 0.63 to 0.83 to 1.32 fold incremental ratio over the past twelve years (Table 3 ).

\section{DISCUSSION}

The pharmacy technician works at three kinds of places in hospitals, primary healthcare centers and medical affairs administration. ${ }^{[13,15]}$ Each sector had a specific job description accordingly. The findings of the study showed that the total number of pharmacy technician works at all types of sectors increased over twelve years, with a binary number with increased 0.16 -fold annually. It is difficult to judge the increments number demand due to the standard of pharmacy technician requirements has not existed. Also, the workload of a pharmacy technician was not reported in the annual $\mathrm{MOH}$ statistical book. The findings showed there was increased with Saudi phar-

\begin{tabular}{|c|c|c|c|c|c|c|c|c|c|c|c|c|c|c|}
\hline \multirow[t]{2}{*}{ Year } & \multirow[t]{2}{*}{$\begin{array}{l}\frac{}{0} \\
\frac{0}{5} \\
\frac{0}{0} \\
\frac{0}{0} \\
\frac{0}{0} \\
\stackrel{0}{0}\end{array}$} & \multirow[t]{2}{*}{ 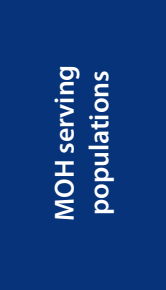 } & \multicolumn{3}{|c|}{ 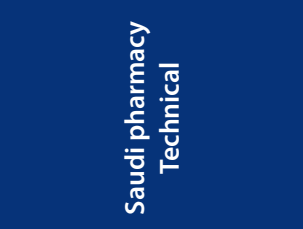 } & \multicolumn{3}{|c|}{ 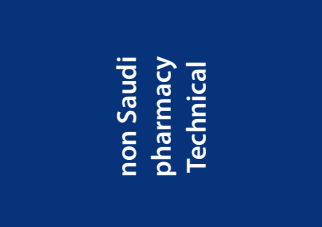 } & \multirow[t]{2}{*}{ 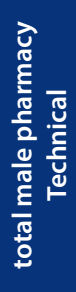 } & \multirow{2}{*}{ 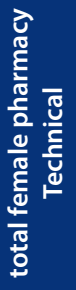 } & \multirow[t]{2}{*}{ 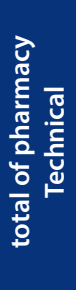 } & \multirow[t]{2}{*}{$\begin{array}{l}\frac{\hbar}{u} \\
\frac{\pi}{0} \\
\frac{5}{5} \\
\frac{5}{0} \\
\frac{0}{0} \\
\frac{0}{2}\end{array}$} & \multirow[t]{2}{*}{ 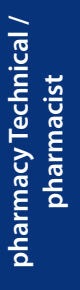 } & \multirow[t]{2}{*}{ 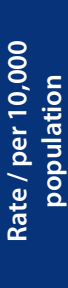 } \\
\hline & & & male & female & total & male & female & total & & & & & & \\
\hline 2006 & $23,678,849.00$ & $14,207,309.40$ & 2,887 & 177 & 3,064 & 744 & 481 & 1,225 & 3,631 & 658 & 4,289 & 636 & 6.7 & 3.02 \\
\hline 2007 & $24,242,578.00$ & $14,545,546.80$ & 2,886 & 217 & 3,103 & 440 & 458 & 898 & 3,326 & 675 & 4,001 & 804 & 5.0 & 2.75 \\
\hline 2008 & $24,807,273.00$ & $14,884,363.80$ & 3,023 & 222 & 3,245 & 331 & 393 & 724 & 3,354 & 615 & 3,969 & 1,065 & 3.7 & 2.67 \\
\hline 2009 & $25,373,512.00$ & $15,224,107.20$ & 3,485 & 386 & 3,871 & 105 & 337 & 442 & 3,590 & 723 & 4,313 & 1,364 & 3.2 & 2.83 \\
\hline 2010 & $27,136,977.00$ & $16,282,186.20$ & 4,724 & 532 & 5,256 & 91 & 353 & 444 & 4,815 & 885 & 5,700 & 1,601 & 3.6 & 3.50 \\
\hline 2011 & $28,376,355.00$ & $17,025,813.00$ & 5,276 & 570 & 5,846 & 112 & 412 & 524 & 5,388 & 982 & 6,370 & 1,487 & 4.3 & 3.74 \\
\hline 2012 & $29,204,842.00$ & $17,522,905.20$ & 5,457 & 813 & 6,270 & 73 & 276 & 349 & 5,530 & 1,089 & 6,619 & 1,661 & 4.0 & 3.78 \\
\hline 2013 & $29,994,272.00$ & $17,996,563.20$ & 5,338 & 805 & 6,143 & 113 & 362 & 475 & 5,451 & 1,167 & 6,618 & 1,915 & 3.5 & 3.68 \\
\hline 2014 & $30,770,375.00$ & $18,462,225.00$ & 7,259 & 796 & 8,055 & 51 & 242 & 293 & 7,310 & 1,038 & 8,348 & 2,239 & 3.7 & 4.52 \\
\hline 2015 & $31,521,418.00$ & $18,912,850.80$ & 7,307 & 889 & 8,196 & 46 & 229 & 275 & 7,353 & 1,118 & 8,471 & 2,389 & 3.5 & 4.48 \\
\hline 2016 & $31,742,308.00$ & $19,045,384.80$ & 7,263 & 904 & 8,167 & 49 & 236 & 285 & 7,312 & 1,140 & 8,452 & 2,714 & 3.1 & 4.44 \\
\hline 2017 & $32,552,336.00$ & $19,531,402.00$ & 7,149 & 912 & 8,061 & 56 & 256 & 312 & 7,205 & 1,168 & 8,373 & 3,853 & 2.2 & 4.29 \\
\hline
\end{tabular}




\begin{tabular}{|c|c|c|c|c|c|c|c|c|c|c|c|c|c|c|c|c|}
\hline Year & Hospital & $\begin{array}{c}\text { No } \\
\text { Beds }\end{array}$ & 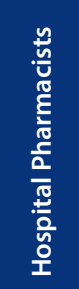 & \multicolumn{3}{|c|}{ 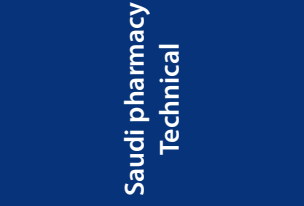 } & \multicolumn{3}{|c|}{ 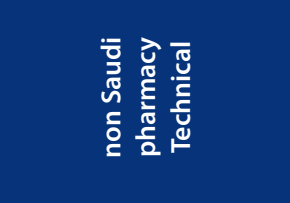 } & 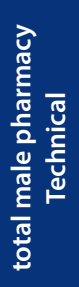 & 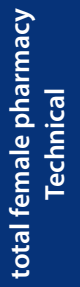 & 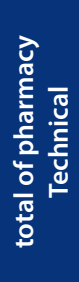 & 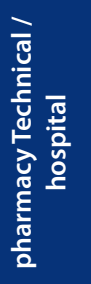 & 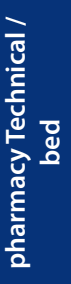 & 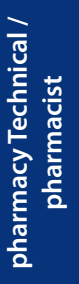 & 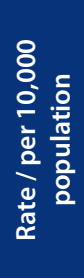 \\
\hline 2006 & 220 & 31,877 & 636 & 1,951 & 120 & 2,071 & 503 & 325 & 828 & 2,454 & 445 & 2,899 & 13.18 & 0.09 & 4.56 & 2.04 \\
\hline 2007 & 225 & 31,420 & 804 & 1,974 & 148 & 2,122 & 301 & 313 & 614 & 2,275 & 461 & 2,736 & 12.16 & 0.09 & 3.40 & 1.88 \\
\hline 2008 & 231 & 31,720 & 1,065 & 2,103 & 155 & 2,258 & 230 & 274 & 504 & 2,333 & 429 & 2,762 & 11.96 & 0.09 & 2.59 & 1.86 \\
\hline 2009 & 244 & 33,277 & 1,364 & 2,439 & 270 & 2,709 & 74 & 236 & 310 & 2,513 & 506 & 3,019 & 12.37 & 0.09 & 2.21 & 1.98 \\
\hline 2013 & 268 & 38,970 & 1,820 & 3,845 & 580 & 4,425 & 82 & 261 & 343 & 3,927 & 841 & 4,768 & 17.79 & 0.12 & 2.62 & 2.65 \\
\hline 2014 & 270 & 40,300 & 2,206 & 5,366 & 589 & 5,955 & 38 & 179 & 217 & 5,404 & 768 & 6,172 & 22.86 & 0.15 & 2.80 & 3.34 \\
\hline 2015 & 274 & 41,297 & 2,389 & 5,432 & 661 & 6,093 & 34 & 170 & 204 & 5,466 & 831 & 6,297 & 22.98 & 0.15 & 2.64 & 3.33 \\
\hline 2016 & 274 & 41,835 & 2,760 & 5,523 & 688 & 6,211 & 37 & 180 & 217 & 5,560 & 868 & 6,428 & 23.46 & 0.15 & 2.33 & 3.38 \\
\hline 2017 & 282 & 43,080 & 3,248 & 5,652 & 721 & 6,373 & 44 & 202 & 246 & 5,696 & 923 & 6,619 & 23.47 & 0.15 & 2.04 & 3.39 \\
\hline
\end{tabular}

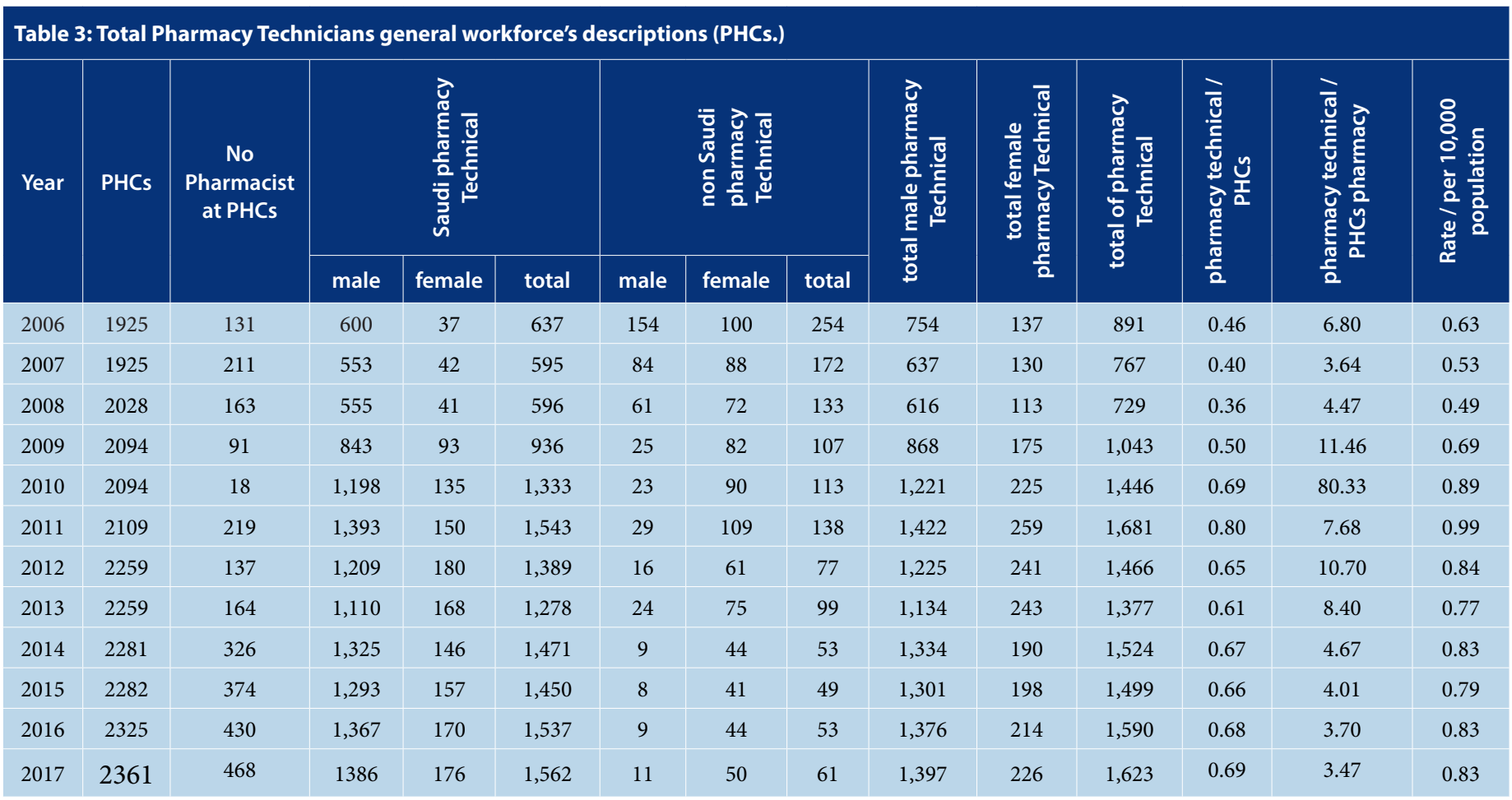

macy technician with increased 0.219-fold increments and at the same time, there were reductions with non-Saudi pharmacy technician with 0.326 -fold reductions. The reductions of a pharmacy technician were faster than increments of pharmacy technician as replacements by 1.48 -fold. That is mean there will be a shortage of pharmacy technician at such point of time. In the comparison of both genders, the male Saudi pharmacy technician increased by 0.2 -fold annually, while reductions of nonSaudi male with 1.1 -fold. It was almost 5.5 times faster in the replacements. The possibility of a male pharmacy technician will be high. In the other word, the Saudi female pharmacy technician by 0.429 -fold increased annually, while the non-Saudi female technician decreased by 0.156 -fold annually. The replacements of Saudi female pharmacy technician with the Saudization program were faster than nonSaudi female pharmacy technician by 2.75 -fold increments. As results, it possible to have over a staff of female pharmacy technician. The findings showed the ratio of a pharmacy technician 


\section{Pharmacy techncian distribution (gender-nationality) 2006-2017}

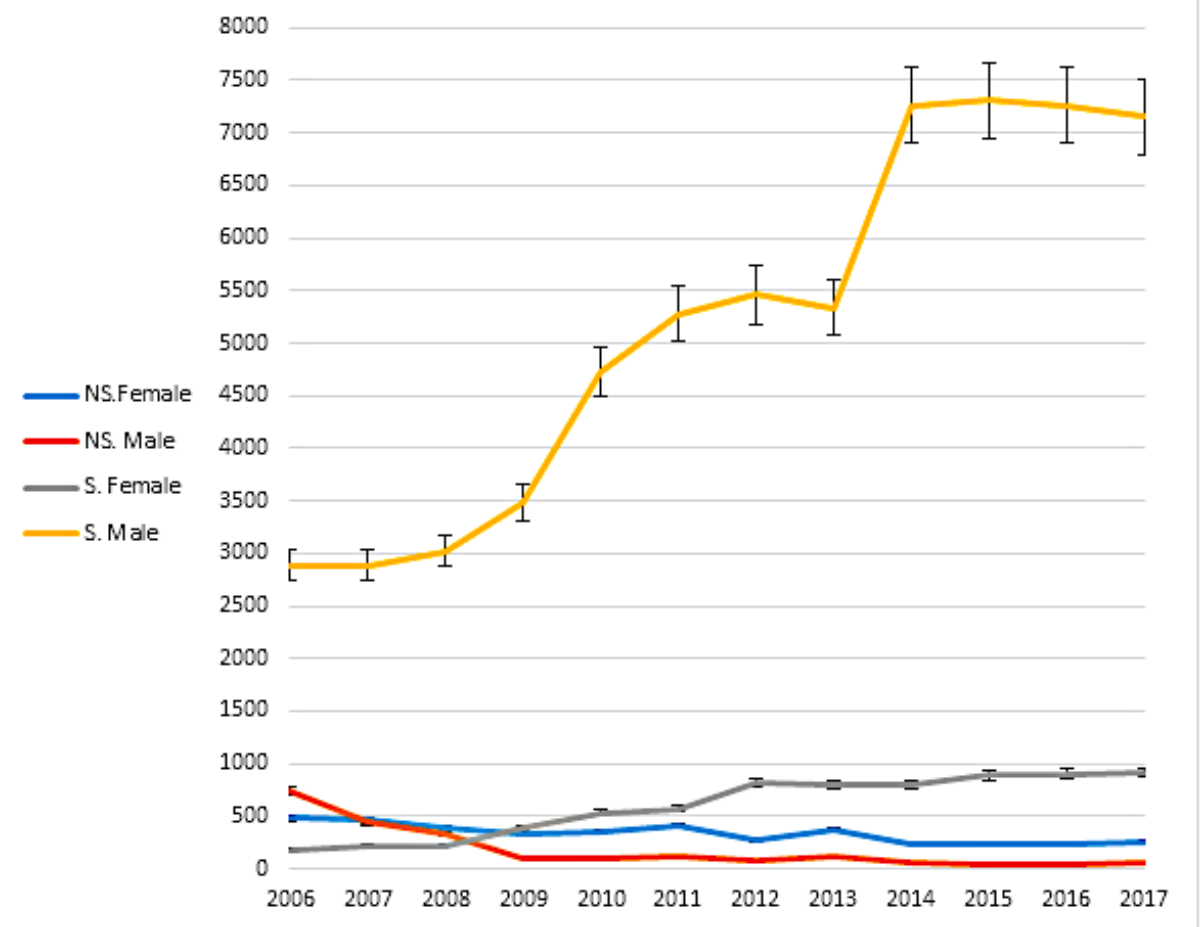

Figure 1: Pharmacy technician nationality and gender (S: Saudi, NS: Non Saudi)

to pharmacy reduced annually by 0.254 -fold. That is related maybe to increase the number of a pharmacist at primary healthcare centers without keeping consideration of constant ratio. However, still the ratio within a range and similar to the previous studies. ${ }^{[29,30]}$ There are increased of pharmacy technician per Saudi populations and that has expected because of double increments of pharmacy technician.

The findings showed the rate of replacements of a hospital pharmacy technician with Saudi nationality by non-Saudi almost the same. That is good to prevent over or under the staff of the pharmacy technician. However, the Saudi male pharmacy technician increased to 0.24 -fold annually, while the reductions in the non-Saudi male pharmacy technician with 0.519 and the subsequent possibility of a shortage of male pharmacy technician in the hospitals. Regarding the Saudi female, pharmacy technician increased quickly while the reductions of nonSaudi female pharmacy technician slowly and possibly of other staff may occur. However, the male pharmacy technician was much higher than female pharmacy technician with different to previous studies with more in the female gender. ${ }^{[1,32]}$ The ratio of a hospital pharmacy technician to pharmacist or pharmacy technician per populations were increased due to an increase in the number of hospital pharmacy technician.
The findings of the study showed that is the number of Saudi pharmacies work at primary healthcare centers increased by 0.215 -fold annually, while reductions in the non-Saudi Pharmacy Technician to 0.346 -fold annually. As results, the replacements of a Saudi pharmacy technician are high and possible of other staff. The Saudi male pharmacy technician of PHCs replacements is lower than hospital by a non-Saudi male pharmacy technician and possibly a shortage of pharmacy will be high. Besides, the Saudi female pharmacy technician replacements almost equal to hospital female pharmacy technician. The ratio of a pharmacy technician to the pharmacist at primary healthcare centers was higher than pharmacist that's related to a low number of pharmacists at primary healthcare centers. The ration of pharmacy technician per populations of PHCs is lower that hospital that's due lower number of pharmacy technician works at PHCs.

The Saudization project was very high implemented with pharmacy technician workforce and very fast and possibly may affect the total number of pharmacy technician and resulted in a shortage or other staff. The planning of a pharmacy technician annually should be revised annually. Besides, the ratio of a pharmacy technician to pharmacist should be implemented in hospitals and PHCs and we would suggest 1:2-1:4 at PHCs and hospital, respectively in the Kingdom of Saudi Arabia.

\section{CONCLUSION}

The current study was the first done in Saudi Arabia and Gulf or Middle East countries. The pharmacy workforces over the past twelve years doubled with cumulative increased of Saudi nationality and both genders. The ration of pharmacy technician to pharmacist decreased with time and should be standardized by the healthcare sector. Further study is required to declare in depth detail of pharmacy technician at all governmental and private healthcare organizations in the kingdom of Saudi Arabia.

\section{ACKNOWLEDGEMENT}

None

\section{CONFLICT OF INTEREST}

The authors declare that there are no conflicts of interest.

\section{ABBREVIATIONS}

KSA: Kingdom of Saudi Arabia; MOH: Ministry of Health; ASHP: American Society of Health-System Pharmacist; PHCs: Primary Healthcare Centers.

\section{ORCID ID}

Yousef Ahmed Alomi org/0000-0003-1381-628X

\section{REFERENCES}

1. Alomi YA, Alghamdi SJ, Alattyh RA. Strategic plan of general administration of pharmaceutical care at ministry of health in Saudi Arabia 2012-2022. J Pharm Pharm Scien. 2015;1(13):1-8.

2. Alomi YA, Alghamdi SJ, Alattyh RA, Elshenawy RA. The evaluation of pharmacy strategic plan in past 2013-2016 and forecasting of new vision 2030 at ministry of health in Saudi Arabia J Pharm Pract Community Med. 2018;4(2):93-101.

3. Ahmed AY, Pharm B, Clin PM. A new guideline on hospital pharmacy manpower in Saudi Arabia. J Pharm Pract Community Med. 2016;2(22):30-1.

4. AlomiYA. Primary care center pharmacy manpower new guidelines in Saudi Arabia. J Pharmaco Clin Res. 2016;1(1):10-3.

5. Alomi YA, Alghamdi SJ, Alattyh RA. Hospital pharmacist workforce in eleven-year 2006-2016 at ministry of health in Saudi Arabia. J Pharm Pract Community Med. 2018;4(1):S115-20.

6. Alomi YA, Alghamdi SJ, Alattyh RA. Hospital pharmacist workforce analysis in eleven-year 20062016 at healthcare institutions in Saudi Arabia. J Pharm Pract Community Med. 2018;4(1):S103-8.

7. Alomi YA, Alghamdi SJ, Alattyh RA. Primary care center pharmacist's workforce in eleven-year 2006-2016 at ministry of health in Saudi Arabia. J Pharm Pract Community Med. 2018;4(1s):S12631.

8. Alomi YA, Alghamdi SJ, Alattyh RA. Primary care centers pharmacist workforce demand in eleven years (2006-2016) and forecasting in fifteen years (2016-2030) at ministry of health in Saudi Arabia. J Pharm Pract Community Med. 2018;4(1s):S121-5.

9. Alomi YA, Alghamdi SJ, Alattyh RA, Ministry A, Box PO. The demand of hospital pharmacist workforce in past eleven years (2006-2016) and forecasting future fifteen years (2016-2030) at all 
healthcare institutions in Saudi Arabia. J Pharm Pract Community Med. 2018;4(1):97-102.

10. Alomi YA, Alhennawi K, Khayayt N. Pharmacy technician workload and workforce requirements at $\mathrm{MOH}$ hospitals during ten years mass gathering haij (2006-2015) in Makah Region, Saudi Arabia. J Pharm Pract Community Med. 2017;3(4s):s75s83.

11. Alomi YA, Alhennawi K, Khayayt N. Pharmacy technician workload and human resources requirements at $\mathrm{MOH}$ hospitals during nine years mass gathering hajj (2006-2014) in Al-Medina Region, Saudi Arabia. J Pharm Pract Community Med. 2017;3(4s):s101-6.

12. Alomi YA, Alhennawi K, Khayayt N. Clinical pharmacy technician and human resources requirements at $\mathrm{MOH}$ primary healthcare centers during ten years mass gathering haij (2006-2015) in Makah and Al-Medina Regions, Saudi Arabia. J Pharm Pract Community Med. 2017;3(4s):s101-6.

13. Health Statistical Year Book. Saudi Ministry of Health. 2017. Available from: http:// www.moh. gov.sa/en/Ministry/Statistics/book/Pages/default. aspx.

14. Saudi Ministry of Health. Health Statistical Year Book. Saudi Ministry of Health. 2016. Available from: http:// www.moh.gov.sa/en/Ministry/Statistics/book/Pages/default.aspx.

15. Saudi Ministry of Health. Health Statistical Year Book. Saudi Ministry of Health. 2006. Available from: http:// www.moh.gov.sa/en/Ministry/Statistics/book/Pages/default.aspx.

16. Saudi Ministry of Health. Health Statistical Year
Book. Saudi Ministry of Health. 2007. Available from: http:// www.moh.gov.sa/en/Ministry/Statistics/book/Pages/default.aspx.

17. Saudi Ministry of Health. Health Statistical Year Book. Saudi Ministry of Health. 2008. Available from: http:// www.moh.gov.sa/en/Ministry/Statistics/book/Pages/default.aspx.

18. Saudi Ministry of Health. Health Statistical Year Book. Saudi Ministry of Health. 2009. Available from: http:// www.moh.gov.sa/en/Ministry/Statistics/book/Pages/default.aspx.

19. Saudi Ministry of Health. Health Statistical Year Book. Saudi Ministry of Health. 2010. Available from: http:// www.moh.gov.sa/en/Ministry/Statistics/book/Pages/default.aspx.

20. Saudi Ministry of Health. Health Statistical Year Book. Saudi Ministry of Health. 2011. Available from: http:// www.moh.gov.sa/en/Ministry/Statistics/book/Pages/default.aspx.

21. Saudi Ministry of Health. Health Statistical Year Book. Saudi Ministry of Health. 2012. Available from: http:// www.moh.gov.sa/en/Ministry/Statistics/book/Pages/default.aspx.

22. Saudi Ministry of Health. Health Statistical Year Book. Saudi Ministry of Health. 2013. Available from: http:// www.moh.gov.sa/en/Ministry/Statistics/book/Pages/default.aspx

23. Saudi Ministry of Health. Health Statistical Year Book. Saudi Ministry of Health. 2014. Available from: http:// www.moh.gov.sa/en/Ministry/Statistics/book/Pages/default.aspx.

24. Saudi Ministry of Health. Health Statistical Year
Book. Saudi Ministry of Health. 2015. Available from: http:// www.moh.gov.sa/en/Ministry/Statistics/book/Pages/default.aspx.

25. American Society of Hospital Pharmacists. ASHP Statement on Pharmaceutical Care. Am J Hosp Pharm. 1993;50(8):1720-3.

26. American Society of Health-System Pharmacists. ASHP guidelines on a standardized method for pharmaceutical care. Am J Heal Pharm. 1996;53(14):1713-6.

27. Saudi Center Board for Accreditation for Healthcare Institutions (CBAHI). Medication Management (MM). In: National Hospital Standards. 2 ${ }^{\text {nd }}$ Edition. Saudi Central Board for Accreditation of Healthcare Institutions. 2016;194-211.

28. The Joint Commission. Comprehensive Accreditation Manuals. Joint Commission Resources. 2016. Available from: http://www.jcrinc.com/ store/publications/ manuals/.

29. Bess DT, Carter J, Deloach L, White CL. Pharmacy technician-to-pharmacist ratios: A state-driven safety and quality decision. J Am Pharm Assoc Pract Pharm Ed. 2014;54(6):648-51.

30. Alkhateeb FM, Shields KM, Broedel-zaugg K, Bryan A, Snell J. Credentialing of pharmacy technicians in the USA. Int $\mathrm{J}$ Pharm Pract. 2011;19(4):219-27.

31. Desselle SP, Holmes ER. Results of the 2015 National Certified Pharmacy. Am J Heal Pharm. 2017;74(13):981-91.

32. Desselle SP, Holmes ER. Final report pharmacy technician workforce survey. 2015;1-49. 